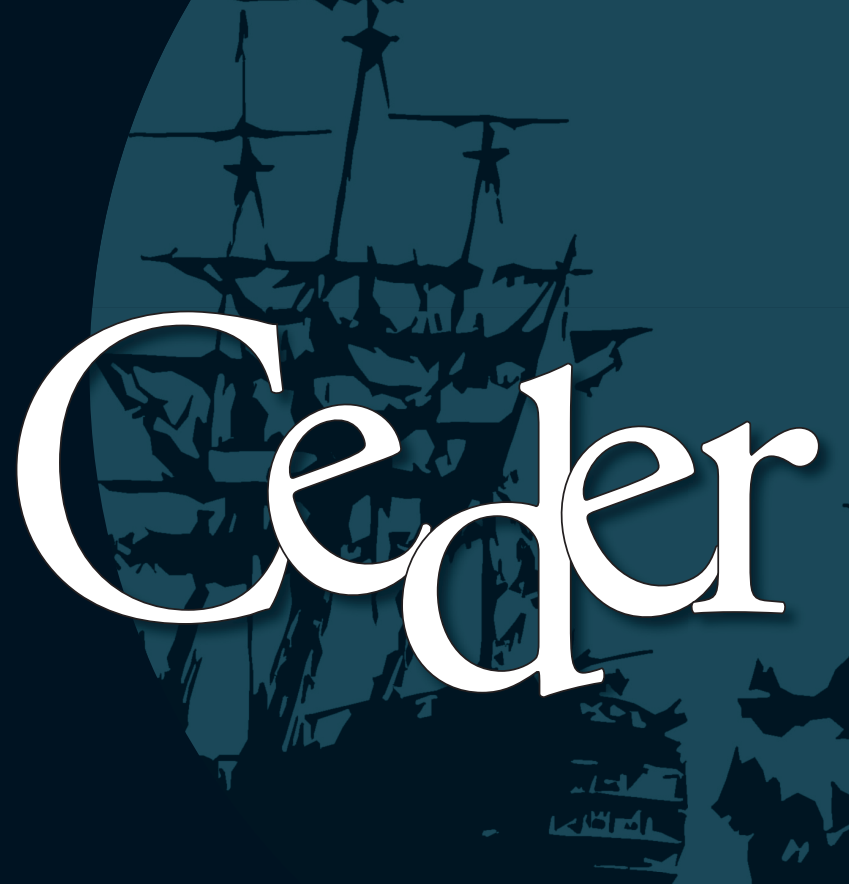




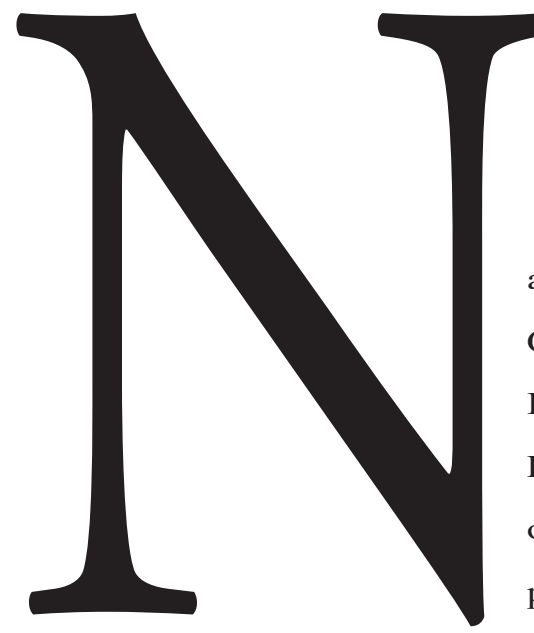

TIAGO C. P. DOS REIS MIRANDA

a segunda semana de novembro de 1807 , com o exército da Gironda a caminho da fronteira, o príncipe regente D. João de Bragança determinou ao secretário de Estado dos Negócios Estrangeiros e Guerra, António de Araújo de Azevedo, nomear o marquês de Marialva e o embaixador D. Lourenço Lima para irem os dois a Paris acordar um tratado. As instruções então redigidas mandavam lembrar pessoalmente ao imperador que "quando a Gram Bretanha soubesse que em Portugal existiam tropas francezas ou hespanholas, ella persuadiria aos habitantes das Colonias Portuguezas que Sua Alteza Real tinha perdido a sua Soberania", sendo, portanto, "mais

TIAGO C. P. DOS REIS MIRANDA é pesquisador do Centro de História de Além-Mar da Universidade Nova de Lisboa.
Neste texto foi mantida a grafia vigente em Portugal.
Júlio Firmino Júdice Biker, Supplemento à Collecção de Tratados Convençōes, Contratos e Actos Públicos Celebrados entre a Corôa de Portugal e as mais potencias desde 1640, T. XIV Lisboa, Imprensa Nacional 1878, pp. 357-67.

2 José Acúrsio das Neves, Obras Completas, vol. 1, Porto, Edicões Afrontamento, 2eed., pp 148-50; João Capistrano de Abreu, Capítulos de História Colonial, 7a ed. Belo Horizonte/São Paulo, Edusp/Itatiaia 1988, pp. 231-2, e Luciano de Castro, A Questão do Amazonas nos Tratados de Paris e Madrid (1797-1801), Porto, Portucalense Editora, S.A.R.L., 1945, pp. 16 e segs. para temer o declarar o Brazil a sua independencia”. Nessa medida, a progressão de Junot aproveitava, de facto, somente aos ingleses. Para Paris, seria decerto mais proveitoso que Portugal deixasse cair o princípio da neutralidade, negociado em dezembro de 1803, por uma aliança política de cunho defensivo, que dispensasse a constituição efectiva de forças conjuntas. Exigindo-se ainda maiores concessões, e chegando a falar-se na necessidade de alguma cedência de territórios, seria possível admitir a troca das ilhas de Timor e Solor pelo enclave europeu de Olivença, ou a simples cessão de uma parte das Guianas que não incluísse afluentes do Amazonas, nem qualquer faixa do litoral a sul do Oiapoque ${ }^{1}$.

A França mantinha um vivo interesse no norte do Brasil desde o começo do século XVII; consolidada a presença em Caiena, passara a nutrir, inclusive, o desejo de posse da totalidade da margem esquerda do Rio Amazonas. A deflagração do conflito europeu, por iniciativa do Directório (1793), havia criado motivos de alguma tensão entre as duas colónias e originado um conjunto de acordos bilaterais, efectivamente resultantes em alterações fronteiriças ${ }^{2}$. Admitir recuar mais um pouco, no quadro de uma possível composição, podia ser 
3 Luciano de Castro, op. cit., pp. 44, 53 e 99-100, e Andrée Mansuy-Diniz Silva, Portrait d'un Homme d'Ełat: D. Rodrigo de Souza Coutinho, Comte de Linhares, 1755-1812, vol. II, Paris, Centre Culturel Calouste Gulbenkian, 2006, pp. 143 e 145.

4 Carlos R. Fernández Liesa, La Cuestión de Olivenza, Valencia, Tirant lo Blanch, 2005, pp. 124-31, in maxime.

5 Cf. Valentim Alexandre, Os Sentidos do Império. Questão Nacional e Questão Colonial na Crise do Antigo Regime Português, Porto, Edições Afrontamento, 1993, p. 158.

6 Júlio Firmino Júdice Biker, op. cit., t. XIV, pp. 360-1.

7 João Manuel Teles da Cunha "Economia e Finanças", in Maria de Jesus dos Mártires Lopes (coord.) O Império Oriental, 1660-1820, T. I, Lisboa, Editorial Estampa, 2006 pp. 339-44 I"Nova História da Expansão Portuguesa", dir. Joel Serrão e A. H. de Oliveira Marques, vol. V

8 Por todos: Artur Teodoro de Matos, Timor Português, 1515 1769: Contribuição para a Sua História, Lisboa, Faculdade de Letras da Universidade de Lisboa e Instituto Histórico Infante Dom Henrique, 1974

9 Charles R. Boxer, "SomeSources for the History of Timor", The Far Eastern Quarterly, vol. 9, no 1, nov./1949, pp. 63-5.

10 Ver Charles R. Boxer, Fidalgos no Extremo Oriente, 15501770: Factos e Lendas de Macau Antigo, trad. de Teresae Manuel Bairrão Oleiro, Lisboa, Fundação Oriente e Museu e Centro de Estudos Marítimos de Macau, 1990, p. 292 Sobre o arquivo de Goa: John LeRoy Christian, "Portuguese India and its Historical Records" in The Hispanic American Historical Review, vol. 25, no 1, feb./1945, pp. 140-51, que Boxer citaria depois em "A Glimpse of the Goa Archives", in Bulletin of the School of Oriental andAfrican Studies, University of London, vol. 14, no 2, 1952, pp. 299-324 visto como um sinal de boa vontade para enterrar de uma vez antigas diferenças, ou apenas como último passo na estratégia de "pequenas cedências" advogada desde há alguns anos por António de Araújo de Azevedo.

Em relação às ilhas da Indonésia, a perspectiva de serem tratadas como moeda de troca por outros domínios não chegava, igualmente, a ser nova. Ministro em Paris (1796-98), o próprio Azevedo aliciara o governo francês com a ideia da entrega de Timor e Solor para chegar a um ajuste mais favorável sobre as Guianas. Luís Pinto de Sousa, secretário de Estado dos Negócios Estrangeiros, e D. Rodrigo de Sousa Coutinho, da Marinha e Ultramar, estiveram, na altura, de acordo sobre essa matéria ${ }^{3}$.

Pondo de lado a questão da aliança política e militar, o que de facto talvez surpreenda nas instruções de novembro de 1807 seja o desejo de recuperar a soberania do território de Olivença, sem permitir debater a integridade do império ultramarino, para além dos estritos parâmetros que se impuseram logo depois do tratado de paz de Basileia (1795). Nem sequer o recente domínio sobre o conjunto dos Sete Povos, adquirido também pela força, em 1801, voltava aliás a ficar sobre a mesa. E nada sugere que tenha tornado a ser discutido nesse contexto ${ }^{4}$

De que maneira se concilia tamanhocuidado na conservação do "sistema imperial"s com a ideia de alienar o direito de posse de Timor e Solor? Por que motivo fora tão fácil chegar a um acordo a esse respeito na segunda metade da década de 1790 , e que razões efectivas justificavam manter semelhante excepção dez anos mais tarde? Qual a importância que tinham as possessões indonésias de Portugal? Noutras palavras, que capital económico, político e mesmo simbólico representavam então?

O texto de 10 novembro de 1807 diz que Timor e Solor eram de grande valia para o império, porque com elas se sustentava o comércio de Macau com a China e com o Japão, por intermédio doópio ${ }^{6}$. Sendo assim, a proposta de paz formulada aos franceses significaria o claro reconhecimento de um menor interesse pelo Extremo Oriente, como um todo, que pelo espaço do Atlântico. Além disso, subalternizava em boa medida a própria presença portuguesa na Índia, onde nos últimos anos se conhecera um vivo incremento das trocas comerciais com os portos do Pacífico ${ }^{7}$. Cenário realmente preocupante.

Vale a pena verificar até que ponto não haverá aqui algum exagero, e qual a razão por que quase se desconhecem essas ideias de transferência de soberania nos anais do Estado da Índia e, sobretudo, nos de Timor.

\section{$\bullet \bullet$}

Os documentos para a história de Timor no período moderno são relativamente pouco numerosos. Em Lisboa, as colecções mais relevantes encontram-se na Filmoteca Ultramarina Portuguesa e no Arquivo Histórico Ultramarino (AHU). Quanto à primeira, vários trabalhos já exploraram o que se acha na série dos Livros das Monções, cobrindo o intervalo do segundo quartel do século XVI a meados do $\mathrm{XIX}^{8}$. O que existe, entretanto, no AHU, é certamente mais volumoso.

Poucos anos depois da Segunda Guerra Mundial, Charles R. Boxer publicou uma nota em que dizia que os papéis relativos a Timor existentes no então Arquivo Histórico Colonial (AHC) constituíam a mais valiosa fonte de informações sobre o tema disponível na Europa. Logo em seguida, dizia igualmente que o acervo se achava bem ordenado e bem conservado?

Considerando que o termo de referência do autor fossem outros arquivos que ele conhecera no Oriente - onde o caruncho, a formiga branca e a humidade eram por certo mais graves ${ }^{10}-$, e tendo em linha de conta que, mesmo em Lisboa, nem a Torre do Tombo, nem a Biblioteca Nacional poderiam ser propriamente classificadas, na altura, como exemplares, é possível pensar que o elogio das condições de trabalho no AHC decorresse de uma certa facilidade de acesso a grandes massas documentais com algum tipo de coerência temática ou 
tipológica, de um conjunto de práticas de armazenagem minimamente adequado, e de uma capacidade de atendimento acima da média. Porque, de facto, no que respeita à descrição do acervo, sessenta anos mais tarde, continuam ainda a faltar elementos que tornem viável o conhecimento do conteúdo de algumas centenas de caixas de avulsos da chamada 1ª Secção do AHU, onde se acha o espólio documental das grandes instituições do Antigo Regime relacionadas com a administração central do império. Entre as séries que actualmente só se conhecem por listas sumárias de cotas e datas extremas, está, por exemplo, a dos avulsos da Índia, composta por quase meio milhar de unidades de instalação. A série de avulsos do reino, certamente também de interesse para a história da Ásia e da Oceania, tem vindo a ser objecto de investimento do Projeto Resgate "Barão do Rio Branco", do Ministério da Cultura do Brasil: em pouco mais de dois anos, foram descritas cerca de 120 unidades de instalação, de um total de quase seiscentas ${ }^{11}$.

Outros dois conjuntos de manuscritos com catálogos mais ou menos recentes são os que se referem expressamente a Macau e a Timor. O primeiro descreve 64 caixas de documentos avulsos, datados de 1587 a $1833^{12}$. O segundo, bastante menor, estendese apenas por seis unidades de instalação, com peças desde do século XVII: são, ao todo, 272 documentos. Desses, cerca de $8 \%$ foram ultimamente identificados nas caixas da Índia ${ }^{13}$.

Para os anos da década de 1800 , existem apenas cinco entradas no catálogo de avulsos do AHU sobre Timor, sendo que um deles é um treslado de um regimento de 1583. Outros dois são requerimentos de militares solicitando a nomeação para o governo da ilha. O terceiro é um ofício do secretário de Estado dos Negócios Estrangeiros e da Guerra encaminhando ao seu colega da Marinha e Ultramar processo referente à candidatura de outro oficial para a mesma ocupação. E, finalmente, o último é o treslado de um auto de devassa feito pelo escrivão da Ouvidoria e do Crime sobre o assassinato de um indivíduo de origem chinesa por um par de soldados ${ }^{14}$. Como se vê, nessa série, parece praticamente não existir testemunhos coevos do período que medeia entre a Guerra das Laranjas e as primeiras invasões dos franceses.

A maior parte das obras que se dedicam à história do Timor português de fins do século XVIII e início do século XIX enfrentam o problema da exiguiidade das fontes. Luna de Oliveira, por exemplo, escreve apenas um único parágrafo sobre esses anos ${ }^{15}$. Sucede, porém, que, logo em seguida, surge com grande destaque nos estudos sobre o tema a referência ao conteúdo de um testemunho absolutamente excepcional, que muito ajuda a suprir as lacunas anteriores: as instruções do vice-rei do Estado da Índia, D. Bernardo da Silveira e Lorena, conde de Sarzedas, ao capitão-de-mar-e-guerra Vitorino Freire da Cunha Gusmão, capitão-geral e governador das ilhas de Timor e Solor, datadas de 28 de abril de 1811. Charles R. Boxer chegou a notar que esse documento esteve na base de praticamente toda a historiografia portuguesa sobre Timor, desde que foi utilizado porAfonso de Castro, no terceiro quartel do século $\mathrm{XIX}^{16}$. Em 1944, o tenente-coronel A. Faria de Morais transcreveu e publicou um registo existente no Arquivo do Governo-Geral do Estado da Índia, em Goa ${ }^{17}$. O Catálogo da Série de Timor do Conselho Ultramarino traz a descrição de uma cópia em 27 folhas, datada de 1830 , com um conjunto de anexos que se encontra incompleto ${ }^{18}$.

D. Bernardo José Maria da Silveira e Lorena dificilmente necessita de ser apresentado em São Paulo: seu nome sobreviveu na designação do caminho que, no início da década de 1790, passou a permitir o acesso ao porto de Santos com muito mais rapidez e facilidade, sendo, portanto, fundamental para o desenvolvimento da cultura do café. Mesmo assim, cabe talvez recordar que se trata de um ilustre fidalgo. Seu assento de baptismo, lavrado em Lisboa, diz que nascera no dia 20 de abril de 1756 , filho de Nuno Gaspar de Távora e D. Maria Inácia da Silveira ${ }^{19}$. O ouvidor da comarca que, anos mais tarde, o acolheu no primeiro governo ultramarino frisou-lhe o facto de ser descendente das Casas dos Condes de
11 Onúcleo exacto de caixas é praticamente impossível de definir antes do final do trabalho, posto que algumas das existentes tendem a aumentar de tamanho e têm de ser desdobradas em duas, devido ao volume das capilhas que normalmente se introduzem para melhor acomodar os documentos.

12 Isaú Santos, Macau e o Oriente no Arquivo Histórico Ultramarino, Lisboa, Instituto Cultural de Macau, 1997, 2 vols.

13 Maria Luísa Abrantes e José Sintra Martinheira, Catálogo da Série Timor do Conselho Ultramarino, Lisboa, Centro de Estudos dos Povos e Culturas de Expressão Portuguesa da Universidade Católica Portuguesa, 2001

14 ldem, ibidem, pp. 197-8.

15 Luna de Oliveira, Timor na História de Portugal, vol. I Lisboa, Agência Geral das Colónias, 1949, p. 266.

16 Charles R. Boxer, "Some Sources for the History of Timor", op. cit., p. 64. Ver também: Affonso Costa, As Possessões Portuguezas na Oceania, Lisboa, Imprensa Nacional, 1867, pp. 55-108.

17 A. Faria de Morais, Sólor e Timor, Lisboa, Agência Geral das Colónias, 1944, pp. 13369

18 Maria Luísa Abrantes e José Sintra Martinheira, op. cit., $p$. 198 (no 164: $27+5$ fls).

19 Arquivo Nacional da Torre Do Tombo, Registos Paroquiais, Lisboa, Santos Reis Magos do Campo Grande, $\lfloor$ - 5-B|F 976| f. $13 \mathrm{v}$. 
Na outra página,

lacre marcado com

as armas de D.

Bernardo José de

Lorena, conde de

Sarzedas, AHU,

Conselho

Ultramarino, Índia,

Cx. 402, doc. $s / n$

20 Oração que no Dia da Posse do III. mo e Ex. ${ }^{\text {mo }}$ S. or Bernardo Jozé de Lorena, do Concelho de Sua Magestade, Governador, e Capitão General da Capitania de S. Paulo, Recitou o Desembargador Miguel Marcelino Velozo e Gama, Ouvidor Geral da Mesma Comarca, Lisboa, NaOfficina de Antonio Gomes, 1789, pp. 11-2

21 Maria Luiza Franco da Rocha, Biografia de D. Bernardo José Maria de Lorena, Conde de Sarzedas, São Paulo, 1940 (Sep. da Revista do Arquivo, № (XIV).

22 Ver, por exemplo: "Os Caminhos do Mar", http://br.geocities. com/ caminhosdomar, no separador relativo à Calçada do Loreno /consultado aos 30 de agosto de 2008).

23 Rómulo de Carvalho, História da Fundação do Colégio Real dos Nobres de Lisboa (176)17721. Coimbra, Atlântida, 1959, pp. 181-7.

24 Oração que [...] Recitou o DesembargadorMiguelMarcelino Velozo e Gama, op. cit., p. 13.

25 Cf. Francisco Adolfo de Varnhagen, História Geral do Brasil, 10@ ed. integral, vol. 2, t. IV, Belo Horizonte/São Paulo, Edusp/Itatiaia, 1981, p. 322.

26 Caio C. Boschi (coord.), Inventário dos Manuscritos Avulsos Relativos a Minas Gerais Existentes no Arquivo Histórico Ultramarino(Lisboa), vol. 2, Belo Horizonte, Sistema Estadual de Planejamento, Fundação João Pinheiro/Centro de Estudos Históricos e Culturais, 1998, pp. 194-283.

27 Joaquim Feliciano dos Santos, Memórias do Distrito Diamantino da Comarca do Serro Frio, 4 a ed. Belo Horizonte/São Paulo, Edusp/Itatiaia, pp. 183

28 Idem, ibidem, p. 192

29 ANTT, Chancelarias Régias, D. Maria I, Lำ 73, fls. 87 e 132

30 ldem, ibidem, ㄴ 75 (F. 3495) fl. 30 lambos os registos de 24 de maio de 1805).
Alvor, de Santiago, dos grandes duques de Cadaval e de Lorena. Particular elogio mereceu, inclusive, a grata memória do seu avô, D. Brás Baltasar da Silveira: porque, para além de ter sido um valoroso soldado nos campos da Guerra da Sucessão Espanhola (1702-14), também governara São Paulo com o mesmo projecto de promover a prosperidade comercial pela melhoria das condições de circulação e transporte ${ }^{20}$.

Ao longo do tempo, correram rumores que questionaram a paternidade de Nuno da Távora. Chegou-se a dizer que o governador era de facto filho ilegítimo deel-reiD. José ou do jovem marquês justiçado, Luís Bernardo de Távora, e sua mulher, D. Teresa: seria, portanto, o autêntico herdeiro do título extinto em 1759. Nesse sentido, concorreriam uma série de histórias familiares e elementos iconográficos revelados em conjunto poruma trineta paulista, Maria Luiza Franco da Rocha, cujo trabalho foi premiado em concurso do Departamento de Cultura da cidade de São Paulo em 1938 ${ }^{21}$. Talvez se alimentem daí algumas das dúvidas que aparentemente ainda subsistem acerca da origem do governador, sobretudo no Brasil $^{22}$.

Para entender a actividade política de D. Bernardo, parece, contudo, mais relevante a circunstância de ter frequentado o primeiro ano de ensino do Colégio dos Nobres (1765-66), onde foi contemporâneo de D. Pedro José de Almeida Portugal, D. Antonio Máximo de Almeida, Francisco José de Horta Machado, D. Rodrigo de Sousa Coutinho e D. José Maria de Sousa Botelho Mourão, entre muitos outros fidalgos e descendentes de homens de negócios em ascensão ${ }^{23}$. O testemunho do ouvidor Miguel Marcelino Veloso indica também que um dos motivos da sua escolha para um governo no Ultramar foram os "[...] seus grandes estudos, e rigorózos exames na Universidade de Coimbra; admirados na corte pela vivacidade do seu engenho, e vastos conhecimentos do Direito Publico, Civil, e Natural [...]"24.

O tempo que esteve em São Paulo deixou satisfeitos os povos e a Coroa ${ }^{25}$. Tanto assim, que se viu depois nomeado para suceder Luís António Furtado de Mendonça, visconde de Barbacena, na capitania de Minas Gerais. Lá viveu quase seis anos, dando conta do dia-a-dia da administração civil e militar, animando os trabalhos de pesquisa de recursos minerais, a exploração e o conhecimento da fauna e da flora, embora em constante confronto com João Inácio do Amaral Silveira, intendente do Distrito Diamantino ${ }^{26}$. Felício dos Santos diria mais tarde que D. Bernardo tendeu a exceder-se: a resposta que terá fornecido, logo ao começo, a uma das cartas do intendente, segundo parece, estaria repleta de "citações, de textos latinos extraídos do Direito Romano e velhos jurisconsultos, [...] em linguagem muitas vezes imprópria e desconhecida" 27 .

Pouco favorável, ainda, é o mesmo cronista, no que respeita às regras de conduta pessoal do ilustre fidalgo. De acordo com o que então se lembrava, em 1801, publicando-se a notícia da viagem de D. Bernardo ao Distrito Diamantino, "muitos pais de família" se retiraram do Arraial do Tijuco, porque "já se conheciam de fama os costumes devassos e dissolutos de Bernardo José de Lorena e sua comitiva: era gente que não poupava a violência quando falsas promessas e astúcias não bastavam para a corrupção de donzelas incautas". Em Vila Rica, D. Bernardo teria, aliás, duas amásias paulistas, por intermédio das quais praticamente tudo se conseguiria nos negócios do governo ${ }^{28}$.

O fim do extenso período de ausência da corte sucedeu em torno de 1804. Foi já nesse ano que se viu nomeado para os lugares de conselheiro de capa e espada do Conselho Ultramarino e deputado da Junta do Tabaco ${ }^{29}$. Meses depois, houve também a mercê dos títulos de conde de Sarzedas e vice-rei do Estado da Índia ${ }^{30}$. Teria então passado a usar um escudo de armas que conjugava o campo de prata e o trio de faixas vermelhas de sua ascendência materna (Silveira), com outro campo do mesmo metal, sob um conjunto de cinco faixas ondadas de azul, e bordadura de ouro com a divisa “Quasqunque findit”, em letras de negro, da parte do pai (Távora); no topo, uma coroa de conde e um urso nascente de prata, armado 
e linguado de vermelho ${ }^{31}$. Subsistem ainda algumas peças de louça e marcas de lacre em que esses símbolos estão enquadrados por jogos de lanças, bandeiras, munições e bombardas (ditos "troféus"), alusivos às responsabilidades militares do seu portador (Ilustração 1) ${ }^{32}$.

O motivo da escolha para o Estado da Índia tanto parece ter sido a sua longa experiência noutros governos ultramarinos, como a vontade de o afastar outra vez de Lisboa. D. José Trazimundo Barreto, sétimo marquês da Fronteira, conta nas suas Memórias que D. Bernardo andara envolvido com uma ordem paramaçónica destinada a fazer esquecer as ideias da Revolução: a Sociedade da Rosa. E apesar de um juiz da Coroa afirmar por escrito que os seus estatutos mais se assemelhavam a "obra de poeta que de conspiradores", acabou dissolvida por Pina Manique, e sua directora, condessa de Oeynhausen, expulsa do reino ${ }^{33}$.

A ordem de embarque do conde de Sarzedas foi certamente menos violenta: o neto dos velhos marqueses de Távora seguia caminho para Goa com um estatuto que já não se usava havia mais de três décadas ${ }^{34}$. Além disso, levava consigo a sisuda incumbência de assegurar a integridade do Império português do Oriente, num momento em que Inglaterra ameaçava poder concluir a tomada dos territórios de Goa, Damão e Diu, militarmente ocupados desde o início do governo de Veiga Cabral $(1799)^{35}$. Ricos ingredientes para a pena de um panegirista de D. Bernardo, que logo em 1805 antecipava em tom de epopeia: "Do Têjo ao Ganges o seu nome vôa..."36.

Francisco António da Veiga Cabral entregou o bastão de comando do Estado da Índia em maio de $1807^{37}$. Em relação à presença das forças britânicas, poucas mudanças parecem ter sucedido, nos meses seguintes, por iniciativa do novo vice-rei. Os gastos então registados sugerem, inclusive, que, praticamente ao longo de um ano, o conde de Sarzedas esteve empenhado acima de tudo na melhoria dos vencimentos dos oficiais do palácio e das tropas disponíveis ${ }^{38}$. Além disso, parece também bastante pro-

\section{Ilustração 1}

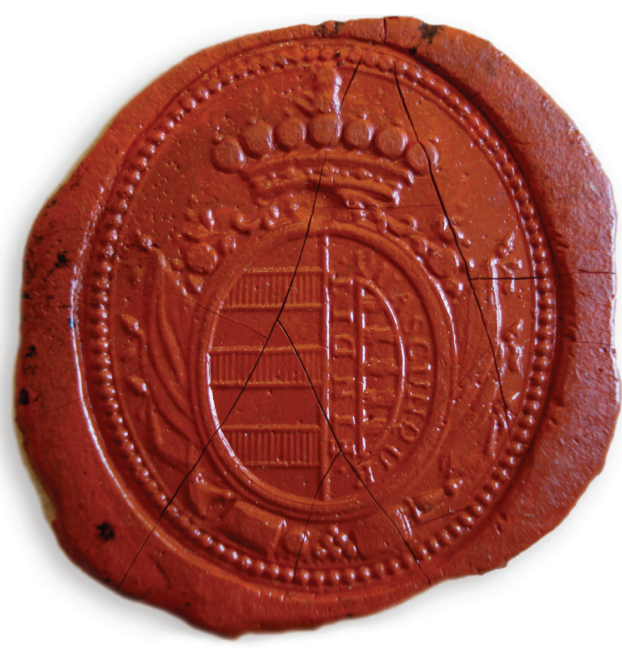

vável que dedicasse alguma atenção à sua casa e aos seus filhos ${ }^{39}$.

As primeiras notícias da abertura de hostilidades da marinha francesa contra navios portugueses circularam no Estado da Índia nos últimos dias de fevereiro de 1808 . E a perspectiva de deposição da Casa Real de Bragança ou de um ajuste de última hora que prejudicasse a aliança com a Inglaterra justificou, nessa altura, um movimento de apreensão de embarcações portuguesas pela marinha britânica. Em meados de maio, apresentou-se em Pangim um enviado da Companhia das Índias Orientais, capitão Schuyler, para comunicar a saída da família real portuguesa para o Brasil e a manutenção da mais perfeita e chegada aliança entre as coroas de Portugal e da Grã-Bretanha. Na mesma visita, aproveitou para expressar as desculpas do governo de Bengala pelos transtornos ultimamente causados nos movimentos marítimos do Estado da Índia, afiançando que, em todo caso, a intenção da Inglaterra nunca deixara de ser a de zelar pelos direitos e interesses de seu antigo aliado. Os próximos dias trariam, porém, uma prova cabal da manutenção da duplicidade do comportamento britânico: a previsão da entrega de todo o governo civil e militar das possessões portuguesas à Inglaterra, de acordo com os termos de uma proposta de convenção de sua inteira iniciativa ${ }^{40}$.
31 Descrição baseada em Anselmo Braamcamp Freire, Brasões da Sala de Sintra, 4e ed., vol. I, Lisboa, Imprensa Nacional/Casa da Moeda, p. 223, e Armaria Portuguesa, 2ed., Lisboa, Cota d'Armas Editores e Livreiros, 1989, pp. 476 e $497-8$

32 Anselmo Braamcamp Freire, Brasões da Sala de Sintra, op. cit. e Armando de Mattos, Manual de Heráldica Portuguesa, Porto, Fernando Machado, 1941, pp. 64-5.

33 Marquês de Fronteira e d'Alorna, Memórias, Coimbra, Imprensa da Universidade, 1928, pp. 14-5 e 189, e A. H. de Oliveira Marques, História da Maçonaria em Portugal, vol. I, Lisboa, Editorial Presença, 1997, p. 300

34 A. J. R. Russell-Wood, "Governantes e Agentes", in Francisco Bethencourt e Kirti Chaudhuri, História da Expansão Portuguesa, vol. 3, Lisboa, Círculo de Leitores, p. 172

35 Simão José da Luz Soriano, História da Guerra Civil e do Estabelecimento do Governo Parlamentarem Portugal, Primeira Ephoca, T. II, Lisboa, Imprensa Nacional, 1867, pp. 444 e segs., e Ernestina Carreira, "Aspectos Políticos", in Maria de Jesus dos Mártires Lopes (coord.), op. cit., T. I, pp. 120-1.

36 Obras Poéticas que Debaixo dos Auspícios do III. mo e Ex.mo Senhor Bernardo José de Lorena, Conde de Sarzedas, do Conselho de S. A. R., Nomeado Vice-Rei, e Capitão General de Mar, e Terra do Estado da India, etc. etc. etc. Manda ao Publico Manoel Joaquim Ribeiro, Professor Regio de Filosofia em Minas Geraes, Lisboa, Na impressão Regia, 1805, p. 36.

37 Cf. Simão José da Luz Soriano, op. cit., Primeira Ephoca, t. II, p. 702, e Frederick Charles Danvers, The Portuguese in India, vol. II, London, W. H. Allen \& Co. Limited, p. 454.

38 João Manuel Teles da Cunha "Economia e Finanças", op. cit., pp. 374-5.

39 Sobre a persistência dos interesses dos condes de Sarzedas no Estado da India, ver: Maria Luiza Franco da Rocha, op. cit., pp. 134-5; e Jorge Forjaz e José Francisco de Noronha, Os Luso-descendentes da India Portuguesa, 2a ed., vol. III, Lisboa, Fundação Oriente, 2003 , p. 588.

40 Ofício (minuta) do [Conde de Sarzedas] a [um Secretário de Estado], [Pangim, post. Junho de 18081, Biblioteca Nacional de Portugal, Colecção Pombalina, 642 (F. 1631), fls. 700-704v; e João Manuel Teles da Cunha, "Economia e Finanças", op. cit., p. 448 
O conde vice-rei recusou-se a aceitar o artigo mais agravante, mas subscreveu por inteiro o resto do texto. Poucos meses depois, oficialmente informado da transferência da corte para o Rio de Janeiro, decidiu explicar por escrito as circunstâncias da sua atitude, junto com a enorme alegria do feliz salvamento do príncipe regente e da possibilidade que assim conhecia de desfrutar do amor dos seus súbditos brasileiros:

"Quando menos esperava tenho a prezente occazião de me prostrar aos pés de S. A. R. o Principe Regente N. S. tendo nos os seus honrados e fieis vassalos no meio de tanta disgraça a summa felicidade de vermos sua Real Pessoa, e toda a Familia salva para sempre dos abomináveis projectos do mais injusto, e ambiciozo de quantos uzurpadores se encontrão na Historia do Mundo, sendo para mim a maior gloria que o mesmo Augusto Senhor achasse a gente da nossa America qual eu muitas vezes tive a honra de lhe dizer por escrito, e por palavras" 41 .

A exposição é extensa e cheia de imagens patéticas e hiperbólicas, sobretudo no que respeita à descrição dos efeitos das contrariedades e dos desgostos vividos sobre a saúde do remetente. Mas, no final, o resultado concreto da actividade do vice-rei parece isento de mácula:

"[...] pode V. Ex. a segurar a S. A. R. que o seu Estado da India se acha sem diminuição alguma do mesmo modo que me foi entregue, em época tão critica e tal que certamente nem o grande Afonso de Albuquerque teria mais dói que eu, se tivesse a infelicidade de se ver nas circunstancias em que eu me vi $[\ldots]$ "42.

41 BNP, PBA 642, fl. 700. Conservam-se a ortografia e a pontuação, desdobrando-se a maioria das abreviaturas e uniformizando-se o uso das maiúsculas.

42 ldem, ibidem, fl. 704

43 Cf. João Bernardo GalvãoTelles, Geração Pombalina. Descendência de Sebastião José de Carvalho e Melo, Lำ 1․ Lisboa, Dislivro Histórica, 2007, pp. 115-53.
Para melhor entender o alcance dessa alusão, cabe notar que a herdeira legal da capela instituída em Lisboa por Afonso de Albuquerque era, na altura, D. Francisca Maria do Pópulo da Silveira e Lorena, irmã do conde de Sarzedas ${ }^{43}$; noutras palavras, a conservação da integridade do Império do Oriente interessava de perto à própria

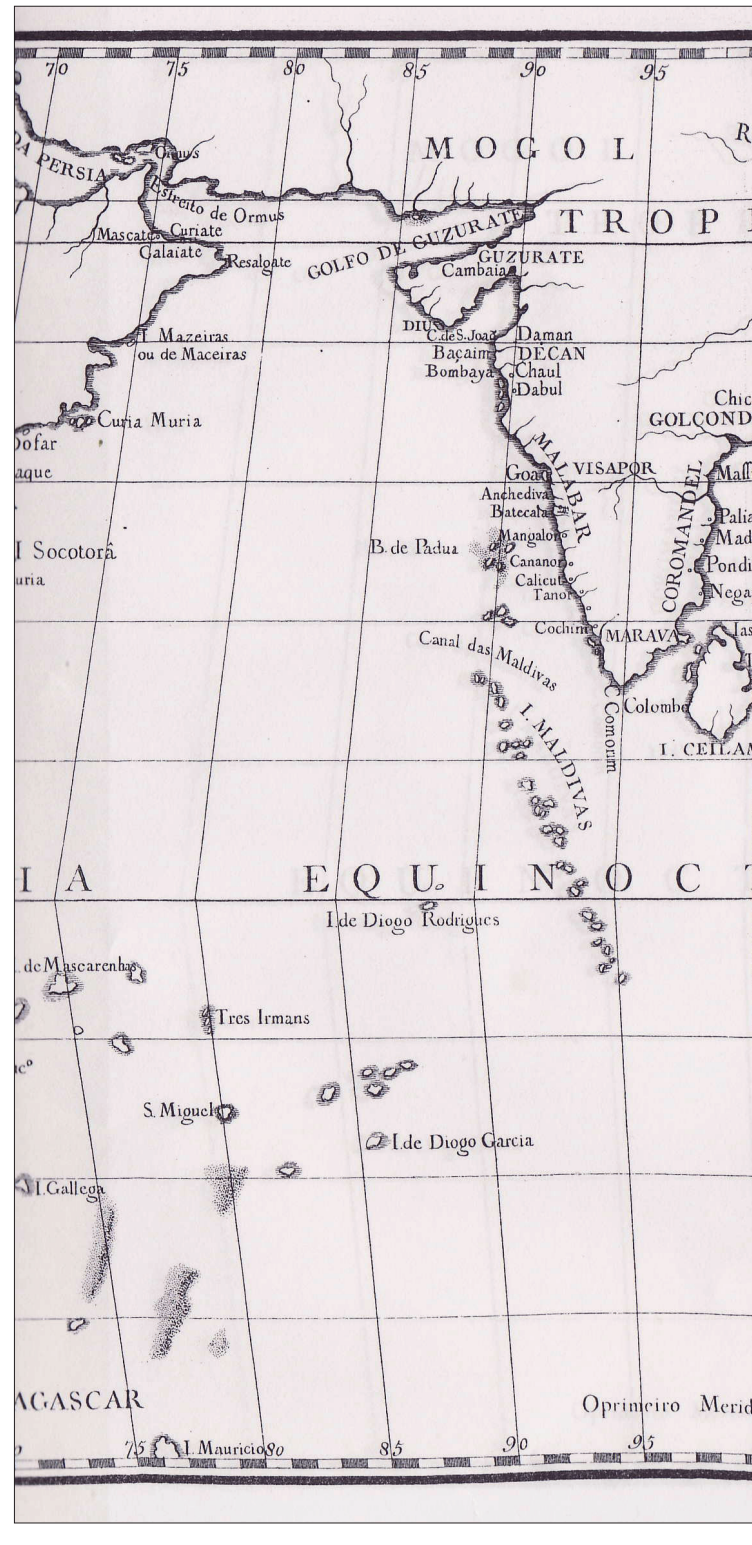

memória simbólica da sua família (Ilustração 2).

Ao longo do ano de 1809, começaram a surgir as condições necessárias a uma efectiva normalização do relacionamento da autoridade portuguesa com as forças britânicas que o ocupavam. E em 1810 teve início o processo de retirada de uma parte dessas forças, só concluído em 1813. De qualquer modo, o aliviar de tensões que então se viveu terá permitido dar nova vida aos serviços centrais e acompanhar um pouco melhor a administração dos vários territórios que dependiam do mando de Goa. 


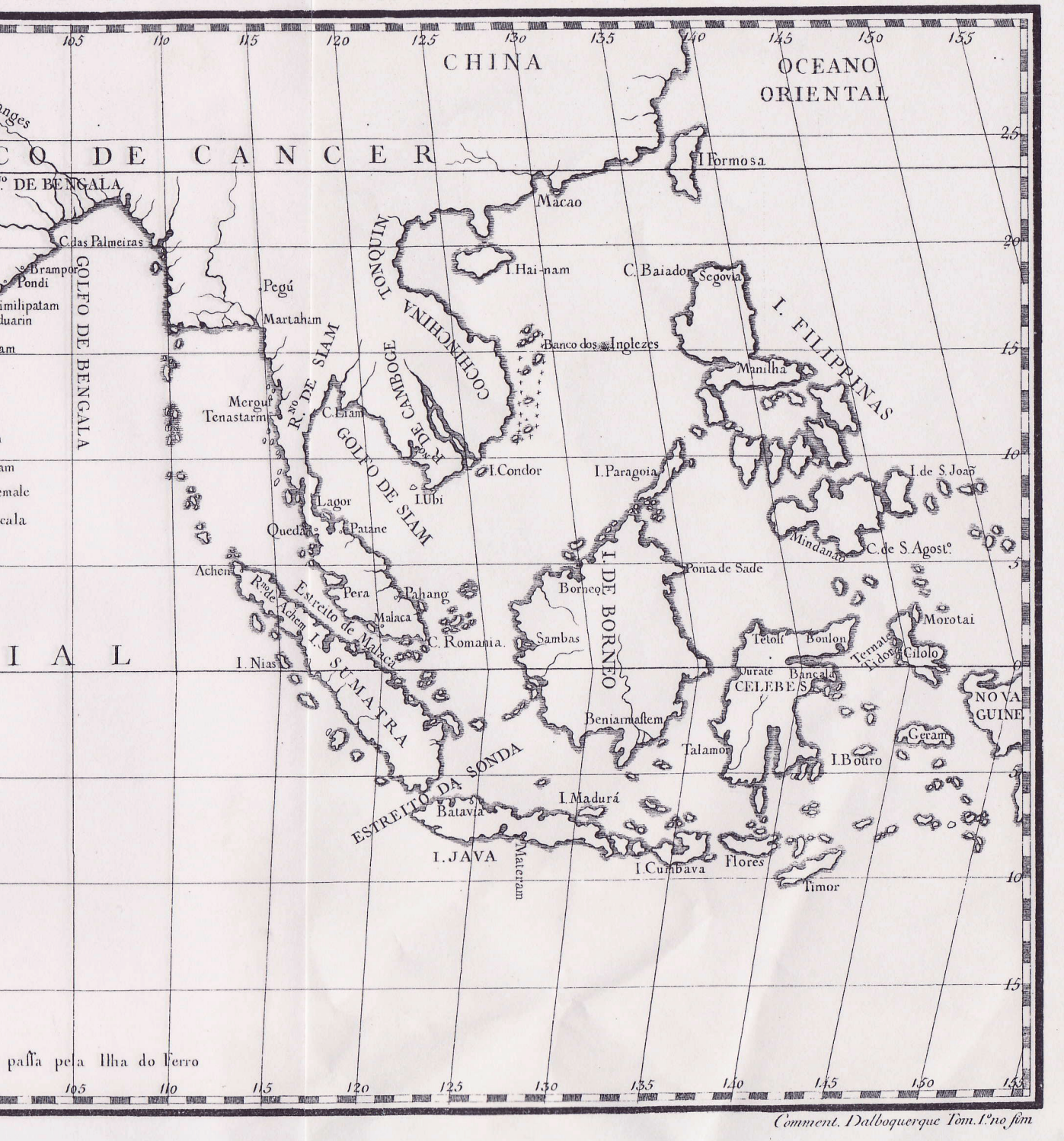

Terras do

Índico em

meados

do século

XVIII. Fonte:

Comentários

de Afonso de

Albuquerque,

Lisboa,

Imprensa

Nacional/Casa

da Moeda,

\section{3}

Reprodução

A preparação das instruções dirigidas ao governador Vitorino Freire da Cunha Gusmão, mais conhecidas como "Documento Sarzedas", sucedeu no preciso momento em que, por ordem do vice-rei, o secretário do Estado da Índia, desembargador Diogo Vieira de Tovar e Albuquerque, passou a redigir um Index Alfabético, Chronologico e Remissivo das ordens de governo existentes no arquivo do governo ${ }^{44}$. O que talvez ajude a entender a espantosa abrangência dos temas tratados e o grau de pormenor de todo esse texto.

As caixas de avulsos da Índia do AHU guardam o ofício com que seguiu para o
Rio de Janeiro uma cópia coeva (entretanto perdida ou deslocada) e uma segunda cópia integral (com a mesma data da que se acha na série Timor) e a transcrição da totalidade dos documentos enumerados no texto instrutório. Trata-se de um conjunto de mais de cem fólios, relativamente bem conservado e, ao que parece, desconhecido da historiografia ${ }^{45}$ (Ilustração 3).

D. Bernardo José de Lorena encaminhou seu ofício ao secretário de Estado da Marinha e dos Negócios Ultramarinos, D. João de Almeida de Melo e Castro, conde de Galveias. E, logo a abrir, o diagnóstico que fez não foi optimista: “O deplorável estado, em que se
44 Diogo Vieira de Tovar e Albuquerque, Index Alfabético, Chronologico e Remissivo das Reaes Ordens Expedidas para - Governo do Estado da India desdeo Ano de 1568, atéo de 1811, e de Muitas Partes Dadas pelo Mesmo Governo á Côrte $[\ldots]$, Nova Goa, Imprensa Nacional, 1918.

45 Arquivo Histórico Ultramarino, Conselho Ultramarino, Índia, Cx. 421 . 


\section{Ilustração 3}

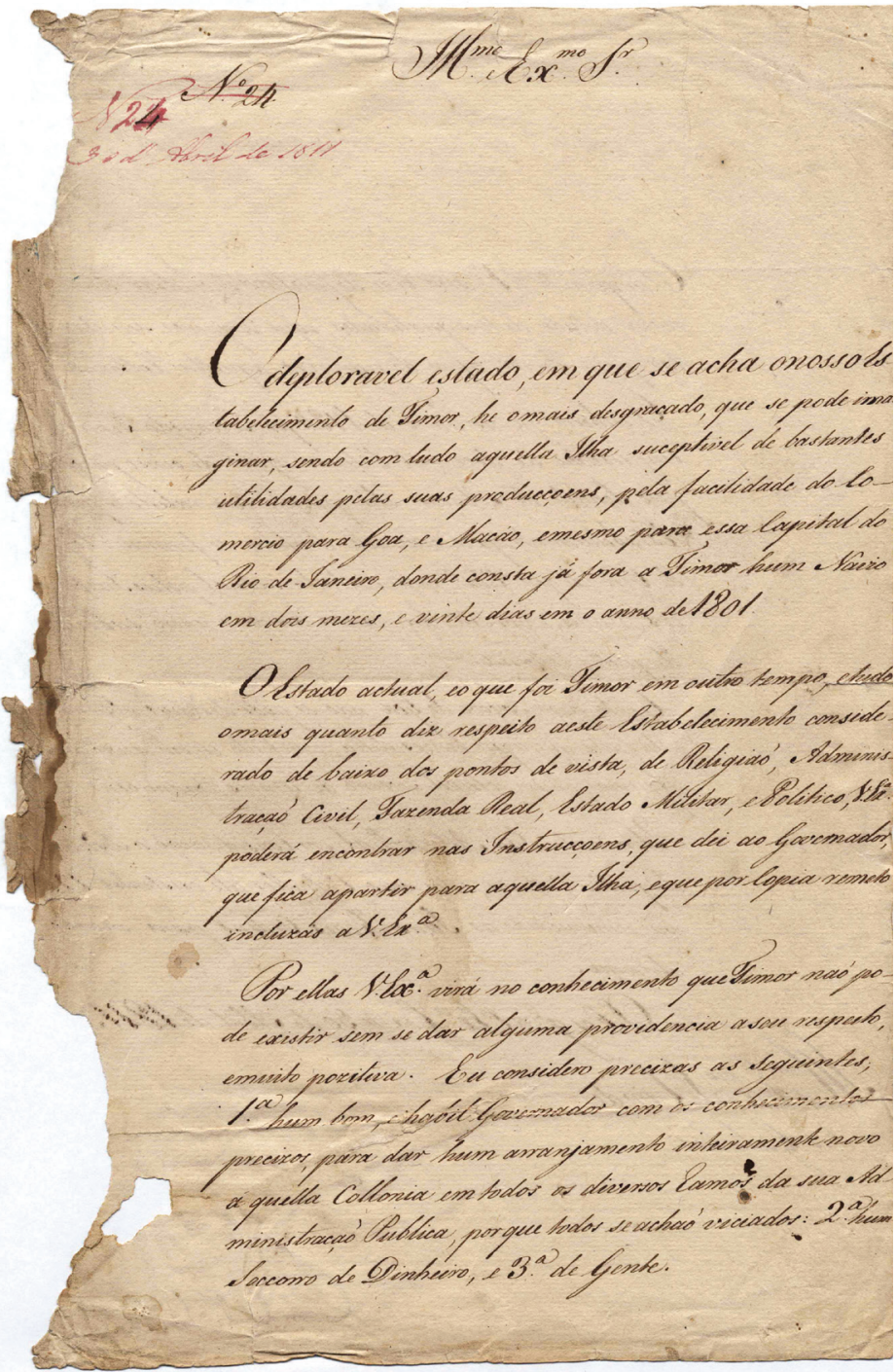

Nesta e na acha o nosso estabelecimento de Timor, he outra página, "Ofício do Conde de Sarzedas ao

Conde das Galveias, Goa, 30 de Abril de 1811", AHU,

Cx. 421, doc. $s / n$ o mais desgraçado, que se pode imaginar". Apesar disso, logo em seguida, reconheceu haver interesse pelos produtos que ali existiam e pela facilidade da sua inserção no comércio directo com Goa, Macau e até mesmo com o Rio de Janeiro, “donde consta já fora a Timor hum navio em dous mezes, e vinte dias em o anno de 1801".

No corpo das instruções, o conde de Sarzedas desenvolvia essas ideias em cinco grandes capítulos: religião, administração civil, Fazenda Real, estado militar e estado político. O primeiro dizia respeito à base formal de toda a empresa ultramarina: a propagação do evangelho. Ora, de facto, o abandono das poucas igrejas edificadas na ilha era praticamente absoluto, subsistindo apenas duas em condições de serem usadas. E oconjunto dos sacerdotes de toda a colónia deveria estar reduzido a umúnico frade, que, na verdade, não se sabia se ainda era vivo.

Esse mesmo problema afectava, aliás, com frequência, os responsáveis pelo governo civil; sobretudo, os capitães. O último deles, António Botelho Homem Bernardes Pessoa, já nomeado pelo próprio Sarzedas, morrera ao serviço, após alguns meses. A maior parte das questões de justiça corria por conta de um ouvidor, que, muito embora não fosse letrado, tinha um estatuto de certo destaque, fortemente sublinhado pelo vice-rei. De resto, um dos maiores obstáculos à existência de um sistema local de governação robusto e fiável eram os constrangimentos legais para solucionar os conflitos que porventura ocorressem entre as mais destacadas autoridades da ilha, sem recorrer ao veredicto das longínquas instâncias de Goa.

O Património Real de Timor consistia unicamente dos direitos da Alfândega, do imposto do vinho e das taxas pagas em géneros ou em dinheiro pelos líderes das comunidades nativas que reconheciam o senhorio europeu. Quase todas essas receitas eram incertas ou estavam em declínio, tendo sido preciso reequilibrar as finanças por intermédio de empréstimos do chamado "cofre de giro". Mascarara-se, assim, o verdadeiro tamanho do défice colonial e alienara-se o capital necessário à promoção do próprio comércio dos produtos locais, que portanto também decaíra. Para além disso, o facto de os antigos registos da Fazenda Real se terem perdido num incêndio das casas do governo, já em finais do século XVIII, privava os novos agentes administrativos dos dados necessários à prossecução de uma estratégia de saneamento realmente adequada e eficaz.

As informações referentes ao estado militar também não eram muitas. E ter a ideia de que, nesse capítulo, alguma vez existira alguma espécie de "arranjo" seria um exagero. Os últimos mapas achados em Goa davam a entender que a quantidade de portugueses nas quatro companhias que constituíam a guarnição de Timor mal 
passava de meia dezena. Todo o restante era formado de homens nativos que os reis aliados escolhiam e destacavam por si.

A longa sequência de folhas que logo em seguida ainda ocupava a maior parte do “Documento Sarzedas" era formada pela colagem de vários relatos sobre os governos da ilha. História repleta de episódios de lutas internas, pequenas revoltas, desfalques, abusos e dissensões. Em várias passagens, surgiam, inclusive, mais uma vez, alguns elementos já explorados nos outros capítulos e volumosos recortes de antigos ofícios ou descrições com particular densidade. Entre eles, lia-se, por exemplo, o seguinte:

"A Ilha tem excelentes producções; tem ouro, tambaque, cobre, enxofar, salitre, salpedra, produz muito sandalo, e bastante cera, trigo, milho, café, bom tabaco, tem muito sagio, tem areca, e muitas qualidades de frutas, como são uvas, figos, bananas, de muitas qualidades, ananazes, excelentes laranjas todo o anno, romãs, atas, manões, melancias, melões, mangas, muita qualidade de verdura, e excelentes repolhos: abunda em búfalos, carneiros, porcos, cabras, tem algumas vacas, e bom algodão"46.

Onze anos volvidos sobre esse testemunho, D. Bernardo José de Lorena mandava proceder à recolha de dados que permitissem ajuizar da melhor forma de combater o acentuado declínio do comércio do sândalo, perante a crescente concorrência britânica, alicerçada na produção dos domínios de Tipu Sahib. Mandava, igualmente, que se revissem os valores dos tributos praticados, para incentivar os sinais existentes de um feliz incremento das actividades agrícolas e uma relação de maior confiança entre os representantes locais da autoridade real e os chefes nativos. Confiança, aliás, bastante merecida: porque, em face de tanto abandonoe de tanto descaso, sobretudo nos últimos anos, a enorme constância dos timorenses dever-lhes-ia valer o tratamento de melhores vassalos de Portugal e melhores cristãos de todo o império.

O ofício enviado para a corte pedia ainda mais três providências: a indicação de um governador que pudesse fazer as reformas indispensáveis ao bom funcionamento da administração; uma boa quantia em dinheiro, para começar a inverter a dependência do saldo do "cofre do giro", e alguma gente adicional, principalmente para o exército. Sem isso, seria bastante difícil que a possessão de Timor tivesse futuro.

A relativa desordem que ainda subsiste entre os papéis das secretarias de Estado de Portugal datados desse período continua a toldar a possibilidade de acesso ao conjunto de trâmites que experimentou o ofício do conde de Sarzedas depois de chegar ao governo do Rio de Janeiro. E não apenas por não se saber com certeza onde se encontram determinados papéis; mas, sobretudo, pela falta de dados sobre a estrutura das séries

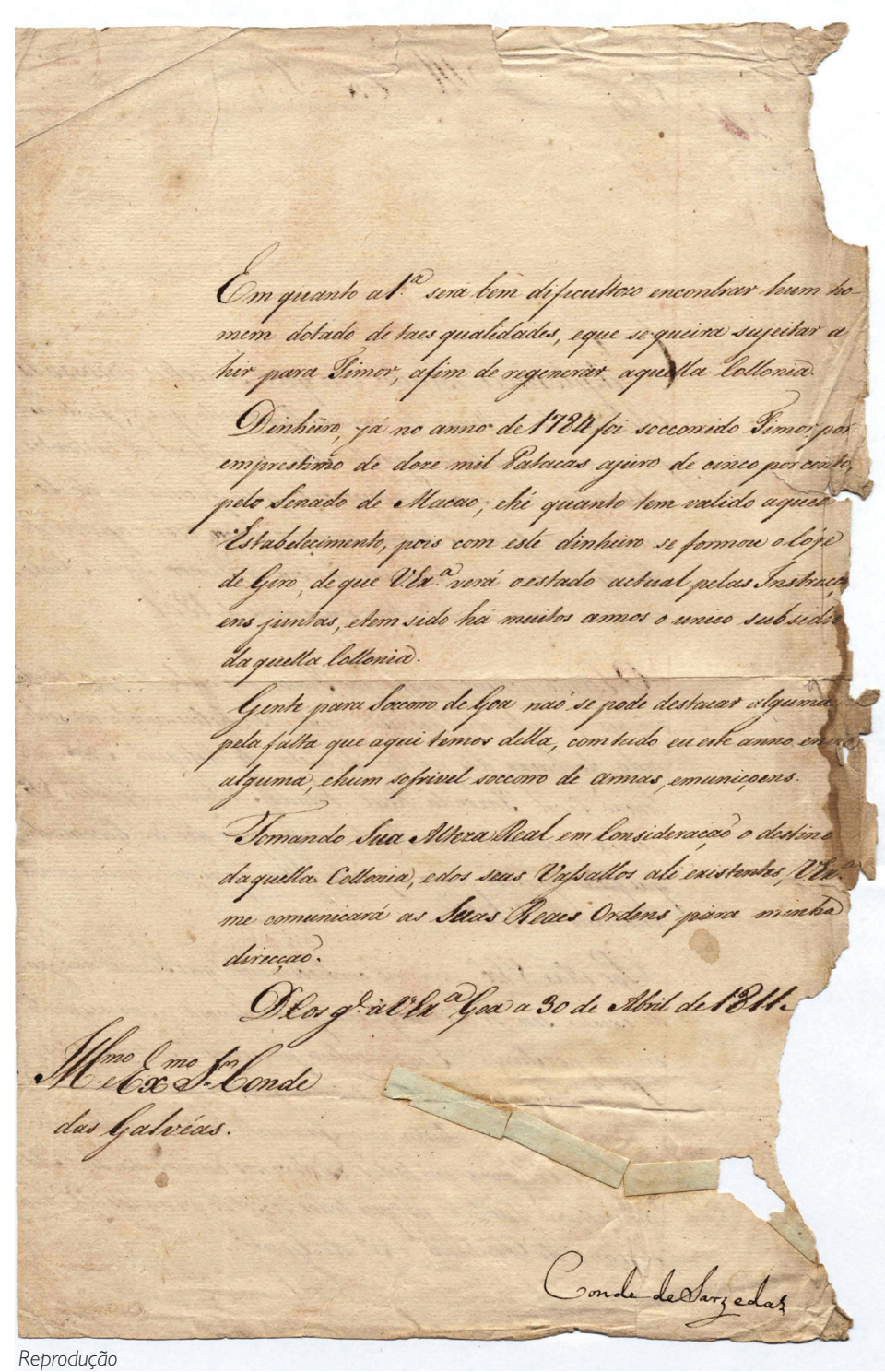

Reprodução

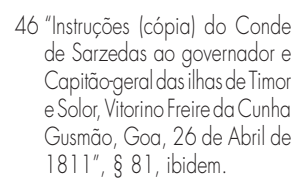

de Sarzedas ao governador e Capitão-geral das ilhas de Timo eSolor, Vitorino Freire da Cunha $1811 "$, § 81, ibidem. 
47 "Escrito do [Conde de Galveias] ao [oficial maior da Secretaria de Estado da Marinha e do Ultramar, José Joaquim da Silva] Freitas, [Rio de Janeiro, c. 1812]", AHU, Conselho Ultramarino, Ultramar, Cx. 22 doc. 1823, cuja indicação agradeço à Dró Érika Simone de Almeida Carlos Dias. Muitas outras peças dessa correspondência estão na série Reino do AHU e na colecção Ministério da Marinha e Ultramar da BNP.

48 AndréeMansuy-Diniz Silva, op. cit., vol. II, pp. 245-8.

49 Júlio Joaquim da Costa Rodrigues da Silva, Ideário Político de uma Elite de Estado. Corpo Diplomático (1777/1793). Lisboa, Fundação Calouste Gulbenkian e Fundação para a Ciência e a Tecnologia, 2002 pp. $1.009-10$ e 1.108

50 Ver, por exemplo: D. Rodrigo de Souza Coutinho, Textos Políficos, Económicos e Financeiros, 1783-1811, introdução e direcção de edição de Andrée Mansuy Diniz Silva, T. II, Lisboa, Banco de Portugal, 1993, pp. 70-2, em que se refere Timor e Solor.

51 "Ofício (registo) do Conde de Aguiar ao Conde de Sarzedas, Rio de Janeiro, 6 de junho de 1812", AHU, Conselho Ultramarino $L^{\circ} 506$, of. 281 .

52 JoséE. Mendes Ferrõo, A Aventura das Plantas e os Descobrimentos Portugueses, Lisboa, Instituto de Investigação Científica e Tropical Comissão Nacional para as Comemorações dos Descobrimentos Portugueses/ Fundação Berardo, 1992, p. 219; Fernando Figueiredo "Timor", in A. H. de Oliveira Marques (coord.). História dos Portugueses no Extremo Oriente 3vol., Lisboa, Fundação Oriente, 2000, p. 711 : Luís Filipe Thomaz, "Timor Leste (Timor Loro Sa'e)", in Enciclopédia Verbo Luso-Brasileira de Cultura, Edicão Século XXI, vol. 28, Lisboa/São Paulo, Editorial Verbo, 2003, col. 217; e idem "Timor", in Maria de Jesus dos Mártires Lopes, op. cit., T. 2 pp. 421-2.

53 José E. Mendes Ferrão, op. cit. passim, eAndrée Mansuy-Diniz Silva, op. cit., vol. II, p. 244. originais e dos modos de funcionamento que, de facto, se foram adoptando, em conjunturas diversas. De qualquer modo, os recentes esforços desenvolvidos no AHU pelo Projeto Resgate permitem agora aceder a um escrito do conde de Galveias, datável do início da década de 1810 , em que se trata do expediente de diversos assuntos da competência da Secretaria de Estado da Marinha e do Ultramar, entre os quais surge a questão de Timor:

"Pareceme, que o Conde de Linhares durante todo o tempo, em que administrou a repartição da Marinha se não ocupou dos negócios de Timor, que durante aquelle tempo, ficarão no mais profundo letargo; precizo saber se isto hé assim como eu penço, e no cazo contrario, as providencias que dêo" 47 .

D. João de Almeida de Melo e Castro chegou a manter correspondência com D. Rodrigo de Sousa Coutinho especificamente sobre os negócios da Ásia. E é conhecido que existiram entre eles sérias diferenças a esse respeito, tendo o comércio de Macau como pomo da discórdia ${ }^{48}$. Em termos gerais, D. João de Almeida era bastante renitente à mudança e tendia a encarar a defesa da integridade do Império português como uma espécie de obrigação imposta pela História ${ }^{49}$. D. Rodrigo estava mais interessado em melhorar o rendimento do que existia e podia ser controlado, admitindo, inclusive, nesse sentido, alterações de estruturas políticas e comerciais $^{50}$. Na passagem transcrita, parece ser claro que D. João de Almeida pretende frisar os problemas decorrentes das animosas ideias do seu adversário, quando, afinal, é a ele que cabe responder pela pasta do Ultramar. E não é improvável que a circunstância por detrás desse passo fosse o ofício do conde de Sarzedas.

A resposta para a Índia saiu, todavia, do gabinete de D. Fernando José de Portugal, conde de Aguiar. Tendo sido levadas ao conhecimento do princípe regente as "detalhadas noções" de D. Bernardo e o longo caderno com as ordens mandadas ao novo responsável do governo de Timor e Solor, o secretário de Estado do reino concordava em lamentar profundamente a "progressiva decadência" daquela colónia, que sem os recursos do "cofre do giro", oriundos de Macau, "teria completamente desaparecido d'entre as nossas assaz reduzidas possessões de Asia". Seria, por isso, muito desejável que se pudessem arranjar os auxílios de gente e de dinheiro requisitados à corte. Infelizmente, porém, não era possível. E a única forma de resolver o problema, a curto e médio prazo, talvez fosse outra vez a partir de Macau. Entretanto, o príncipe regente confiava que o conde vice-rei continuasse a manifestar todo o seu zelo no acompanhamento do assunto, assegurando, com especial atenção, “que os governadores se ocupem mais do melhoramento da colónia, do que dos seus particulares interesses" 51 .

O pouco que se sabe da história de Timor nos anos seguintes sugere ter passado a existir um maior número de instâncias políticas efectivamente empenhadas no acompanhamento da sua administração, ainda que os meios disponíveis permanecessem escassos. Em torno de 1815, a grande novidade local foi o início das roças de mandioca e cana-de-açúcar e a grande expansão do cultivo do café. Cogita-se que as sementes usadas nessa profunda mudança de estrutura produtiva tivessem origem em Java ou no Brasil. Mas faltam ainda elementos que o comprovem $^{52}$. Além disso, quanto ao Brasil, os mais relevantes indícios que se conhecem sobre transferências de espécies botânicas no Império português dessa altura apontam movimentos de sentido contrário ${ }^{53}$.

O que de facto parece ser certo é que a perspectiva sobre a permanência da presença portuguesa em Timor após a intervenção do conde de Sarzedas e ao fim do período das guerras napoleónicas era pelo menos um pouco melhor.

\section{$\bullet \bullet \bullet$}

A embaixada do marquês de Marialva ficou aquém dos Pirenéus. Quando, em meados de novembro de 1807, chegou a Madrid, uma primeira divisão do exército francês, sob o comando do general Delaborde, ti- 
nha já penetrado em Portugal. Não houve, portanto, lugar a discutir com Napoleão Bonaparte uma qualquer aliança política, nem, muito menos, a questão da cedência de territórios ultramarinos. Os episódios que se seguiram foram, de facto, a perda do reino, a proclamação de Junot e a deputação a Baiona. Estando nela integrado, D. Pedro José Joaquim de Meneses pôde apenas prestar vassalagem ao imperador ${ }^{54}$.

O relativo segredo de todo o negócio, a dispersão provocada pelo tempo de guerra e as dificuldades da correspondência com o Oriente devem ter impedido que o teor da proposta de António de Araújo de Azevedo chegasse aos ouvidos do conde de Sarzedas e, de um modo geral, ao Estado da Índia. Mesmo no seio da corte, poucos deviam saber do assunto. De qualquer modo, nesse preciso momento, a hipótese de abandono de uma ilha longínqua para viabilizar um acordo de paz que assegurasse o respeito pela integridade do território do reino português, não seria de prever que gerasse alarido. E o conhecimento da situação existente em Timor, em seus vários aspectos, facilitava bastante o projecto.

Com a mudança da corte do Rio de Janeiro, a decantada vontade de conservação de todo o conjunto ultramarino tendeu a tornar-se ainda mais forte, passando a haver o intento de aproveitar todas as brechas viáveis para tomar a ofensiva sobre o inimigo. Por vezes, não só o francês: como comentava o conde Galveias ao seu amigo Sarzedas, por carta de junho de 1809, a guerra alastrava inclusive aos botocudos ${ }^{55}$. Entretanto, fora da América do Sul, a capacidade de intervenção militar, ou mesmo política, era muito reduzida.

Ainda no tempo em que D. João VI estava no Rio, os holandeses entraram no território português de Timor e tomaram para si Atapupu (1818). O impacto dessa notícia parece ter motivado outra vez um novo cuidado na nomeação das autoridades locais e no ajuste da estrutura de produção para o comércio externo. Mas os progressos continuaram morosos ${ }^{56}$.

Anos mais tarde, José Acúrsio das Neves queixava-se do facto de Portugal manter em Timor e Solor "alguns insignificantes estabelecimentos", que praticamente não possuíam qualquer relação com os outros territórios do império. E, nesse estado de quase abandono, pouco valiam. De qualquer modo, olhando para a frente, seria desejável poder conservá-los ${ }^{57}$.

Opiniões bastante diversas chegaram depois a ser veiculadas com algum desassombro. Entre elas, a de Oliveira Martins, em 1880: “Timor não é coisa nenhuma; e melhor fora abandonar por uma vez, a troco de qualquer preço, este pedaço de ilha a que se não ligam tradições nem interesses". À semelhança de 1811, faltavam então os recursos e a população necessária para investir numa terra demasiado distante e cobiçada por uma potência mais rica ${ }^{58}$.

Os longos debates que antecederam a bancarrota de 1892 tornaram a apontar no mesmo sentido. Aúnica grande diferença foi chegar-se a fazer um elenco de territórios a alienar: numa só assentada, deputados e jornalistas propuseram a Guiné, Ajudá, Cabinda, Moçambique, Macau e Timor. Falou-se, inclusive, na venda da Índia. Mas a reacção fez-se ligeira, e baseou-se nas mais variadas razões, a que se juntaram perguntas com séculos de história: "Por que preço se venderia Goa, que Affonso de Albuquerque escolheu para seu derradeiro descanso? Por que preço se venderia o tumulo de S. Francisco Xavier?"59. E tal como já sucedera noutros contextos, a única resposta aceitável foi o silêncio ${ }^{60}$. O próprio Oliveira Martins passou a usar argumentos semelhantes ${ }^{61}$.

Tendo perdido uma parte importante dos seus domínios mais periféricos na década de 1850, Timor conservou-se sem grandes mudanças, em mãos portuguesas, ao longo de todo o restante período monárquico, da Primeira República, do salazarismo e do governo de Marcello Caetano, sob o peso do "mito da herança sagrada"62. A intromissão da Indonésia dificultou o processo de independência política e a sublimação colectiva do sentimento de perda. Porque, de facto, no plano simbólico, o território português de Timor acabou por ser o último a abandonar o império colonial. Que só assim se enterrou.
54 Simão José da Luz Soriano, op. cit., Primeira Epocha, t. II, p. 662.

55 "A Gazeta que daqui hás-de receber te certificará do sucesso da nossa expedição a Cayena, que se rendeo às forças de S. A. $R$., e pelas precedentes em que se publicou o manifesto contra os botecudos veras, que não hé guerra de grande cuidado, mas sim, que occasione despeza - que comtudo nas actuaes circunstancias não deixa de ser attendivel, maiormente não se tendo ainda conseguido outra alguma vantagem, alem da aprehensão de algumas velhas, que D. Rodrigo aqui nos mostrou, como outros tantos tropheos". Carta do conde de Galveias ao [Conde de Sarzedas], Rio de Janeiro, $14 \mathrm{de}$ junho de 1809, BNP, PBA633, fls. 194v-195. Sob outro ponto de vista: Manuela Carneiro da Cunha (org. l, História dos Indios no Brasil, 2a ed., São Paulo, Companhia das Letras, 1998 pp. 141-2 e 146

56 Fernando Figueiredo, "Timor" op. cit., pp. 711 -4.

57 José Acúrsio das Neves, op. cit., vol. 4, pp. 459-60

58 Oliveira Martins, O Brasil e as Colónias Portuguesas, 7a ed., Lisboa, Guimaraes \& C. $\stackrel{\text {. }}{ }$ Editores, 1978, p. 166

59 Chrystovam Ayres, A Venda da India, Lisboa, Imprensa Nacional, 1891, p. 9, e F. A. Oliveira Martins, O "Ultimatum" Visto por António Enes, Lisboa, Parceria A. M. Pereira, 1946, pp. CLXXIV-CLXXV

60 Ver Tiago C. P. dos Reis Miranda, "La Dimension Européene de la Pensée Politique au Portugal: 1706-1777", in Arquivos do Centro Cultural Calouste Gut benkian, $n^{\circ}$ XLIII, Lisboa/ Paris, pp. 199-207.

61 Cf. Valentim Alexandre, Velho Brasil/Novas Áfricas-Portugal e o Império (1808-1975), Porto, Edições Afrontamento, 2000, pp. 163-79.

62 ldem, ibidem, pp. 219-29 